\title{
Factors That Delay COPD Detection in the General Elderly Population
}

\author{
Jun Horie RPT MSc, Shin Murata RPT PhD, Shinichiro Hayashi MD PhD, Jun Murata OTR PhD, \\ Junya Miyazaki RPT MSc, and Katsuhiko Mizota RPT MSc, and Etsuo Horikawa PhD
}

\begin{abstract}
BACKGROUND: In patients with COPD, early detection and rapid treatment are essential to prevent its progression and exacerbations. OBJECTIVE: To identify factors that delay COPD detection. METHODS: We conducted a cross-sectional study of elderly COPD patients and healthy subjects in rural Japan. We measured respiratory and physical function (hand grip force, maximum inspiratory pressure, maximum expiratory pressure, total trace length, and toe grasp force), walking ability, and quality of life (QOL, measured with a visual analog scale). We conducted spirometry in 408 subjects, whom we divided into 2 groups: those whose ratio of $F E V_{1}$ to forced vital capacity (FVC) was $<70 \%$ (the airway-obstruction group, $n=60$ ), and those whose $\mathrm{FEV}_{1}$ / FVC was $\geq 70 \%$ (the healthy-subjects group, $n=348$ ). To avoid confounding, we then matched 60 subjects from the healthy-subjects group to the 60 in the airway-obstruction group for age, sex, height, and smoking history, so both groups had 60 subjects. RESULTS: Physical function was significantly inferior in the airway-obstruction group. Variables reflecting instantaneous walking ability (maximum walking speed and walking time in the $10-\mathrm{m}$ hurdle walk) were significantly inferior in the airway-obstruction group, but there were no significant differences in 6-min-walk test, which reflects walking endurance, or in QOL. CONCLUSIONS: Walking endurance, QOL, and proximal muscle strength in the extremities of patients with COPD were well preserved, which prevented detection of COPD and hampered the subjects' motive for seeking medical care. In consequence, lack of awareness impeded the early detection of COPD. In primary healthcare for the general elderly population, spirometry is much easier to conduct than physical function tests, so we recommend that spirometry screening programs for early-stage COPD detection and staging. Key words: airway obstruction; chronic obstructive pulmonary disease; COPD; elderly; quality of life; 6-minute walk test; walking; primary healthcare. [Respir Care 2011;56(8):1143-1150. (C) 2011 Daedalus Enterprises]
\end{abstract}

\section{Introduction}

Initiating the treatment of COPD as soon as possible is recommended, utilizing smoking cessation, vaccination, pharmacotherapy, and avoidance of risk factors. ${ }^{1-3}$ In respiratory rehabilitation the prompt initiation of treatment is considered more effective with high-load endurance train-

\footnotetext{
Mr Horie presented a version of this paper at the 45th Congress of the Japanese Physical Therapy Association, held May 28, 2010, in Gifu, Japan.
}

The authors have disclosed no conflicts of interest.

Correspondence: Jun Horie RPT MSc, Department of Rehabilitation, Nishikyushu University, Ozaki 4490-9, Kanzaki-cho, Kanzaki, Saga 8428585, Japan. E-mail: horiej@nisikyu-u.ac.jp.

DOI: $10.4187 /$ respcare.01109 Japan. 
ing $^{4,5}$ that is ongoing 6 and takes into consideration costbenefit performance. ${ }^{7}$ In Japan, the Nippon COPD Epidemiology (NICE) study revealed that only a very small portion of patients with COPD are diagnosed with the disease, and that many people have undiagnosed COPD in the general population. In Japan, approximately 5.3 million individuals over age 40 are estimated to have COPD. ${ }^{8}$

Insidious and ordinary clinical symptoms (eg, chronic cough and chronic sputum) are often considered trivial by people with COPD, which delays COPD detection..$^{9,10}$ Pinto-Plata et al assessed COPD patients' exercise performance according to the Global Initiative for Chronic Obstructive Lung Disease (GOLD) criteria and found no significant difference in exercise performance between the control group and the stage I COPD group; however, there were significant differences between the control group and the stage II through stage IV COPD groups. They concluded that detection of COPD patients via measurement of physical performance is difficult. ${ }^{11}$

The objective of the present study was to identify factors that delay COPD detection in the general elderly population. We measured respiratory and physical function, walking endurance (via 6-minute walk test) and instantaneous walking ability, exercise performance, quality of life (QOL), and ability to conduct activities of daily living (ADL) in elderly COPD patients and healthy subjects in rural Japan.

\section{Methods}

This cross-sectional study was approved by the ethics review board of Nishikyushu University. All subjects gave written informed consent after receiving verbal and written explanations that enrollment was voluntary, he/she would not suffer any disadvantage by not participating, and he/she was authorized to withdraw consent at any time.

\section{Subjects}

Between August 2008 and October 2009 we screened 634 elderly residents in a rural area of Fukuoka, Japan, who participated in a health promotion program. The screening included careful medical history, including smoking status, exposure to second-hand smoke, personal and family history of asthma, ADLs, and QOL. We excluded those who had a diagnosis of a respiratory disease (including respiratory tract infection); residents with medical or family history of asthma; residents who had painful diseases including joint disorders that impair gait; residents who had a severe medical complication; residents who had markedly decreased physical performance; and residents who were incapable of fully understanding the objective and methods of the study. We enrolled 437 subjects.

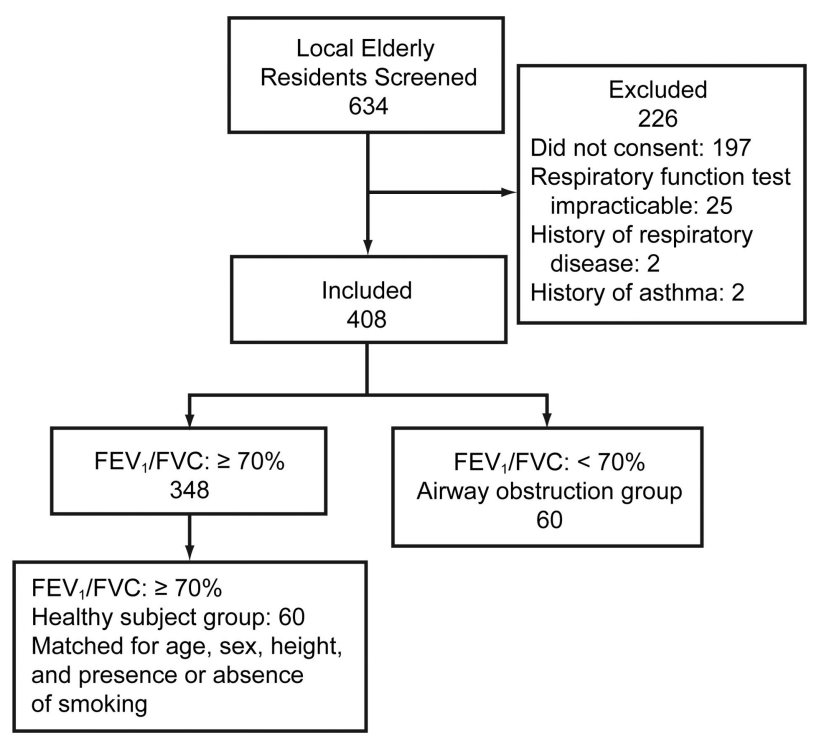

Fig. 1. Flow chart.

\section{Withdrawals and Post-Testing Exclusions}

Of the 437 subjects who undertook spirometry, 29 had difficulty obtaining precise spirometry results, and they were excluded. The 408 remaining subjects were assigned to 2 groups: those whose ratio of $\mathrm{FEV}_{1}$ to forced vital capacity (FVC) was $\geq 70 \%$ (the healthy-subjects group, $n=348$ ), and those whose $\mathrm{FEV}_{1} / \mathrm{FVC}<70 \%$ (the airway-obstruction group, $n=60$ ) (Fig. 1). To avoid confounding, we then matched 60 subjects from the healthysubjects group to the 60 in the airway-obstruction group for age, sex, height, and smoking history, so both groups had 60 subjects. These 120 subjects and the study staff (other than the author who performed spirometry [JH]) did not know the subjects' group assignment. Table 1 shows the cohort's baseline characteristics.

\section{Cognitive Function Assessment}

We assessed cognitive function with the Mini-Mental State Examination, which is a widely used simple assessment scale for cognitive state. ${ }^{12}$

\section{Respiratory Function Testing}

Spirometry (Autospiro AS507, Minato, Osaka, Japan) was conducted by a highly qualified pulmonary function technician $(\mathrm{JH})$. The precision of the spirometry measurements was verified with the spirometer's software, which determined the forced expiration variables, and the flowvolume curves were printed. At least 2 spirometry maneuvers were performed, and the best value was recorded. 
Table 1. Baseline Characteristics of 120 Elderly Residents in Rural Japan

\begin{tabular}{|c|c|c|c|}
\hline & $\begin{array}{l}\text { Healthy Subjects } \\
\quad(n=60)\end{array}$ & $\begin{array}{c}\text { Airway-Obstruction } \\
\text { Subjects } \\
(n=60)\end{array}$ & $P$ \\
\hline Male/female, no. & $21 / 39$ & $21 / 39$ & \\
\hline Smoker/nonsmoker, no. & $7 / 53$ & $7 / 53$ & \\
\hline Second-hand smoke exposure, no. & 29 & 28 & \\
\hline Age $(y)$ & $76.3 \pm 1.8$ & $76.8 \pm 6.8$ & .53 \\
\hline Height $(\mathrm{cm})$ & $152 \pm 8$ & $151 \pm 8$ & .85 \\
\hline Weight $(\mathrm{kg})$ & $55.1 \pm 9.1$ & $50.7 \pm 8.4$ & .004 \\
\hline Body mass index $\left(\mathrm{kg} / \mathrm{m}^{2}\right)$ & $24.0 \pm 3.1$ & $22.1 \pm 2.6$ & $<.001$ \\
\hline $\mathrm{FVC}(\mathrm{L})$ & $2.16 \pm 0.47$ & $2.01 \pm 0.67$ & .23 \\
\hline FVC (\% predicted) & $92 \pm 16$ & $87 \pm 18$ & .10 \\
\hline $\mathrm{FEV}_{1}(\mathrm{~L})$ & $1.68 \pm 0.38$ & $1.20 \pm 0.47$ & $<.001$ \\
\hline $\mathrm{FEV}_{1} / \mathrm{FVC}(\%)$ & $79 \pm 6$ & $61 \pm 7$ & $<.001$ \\
\hline $\mathrm{FEV}_{1} / \mathrm{FVC}(\%$ predicted $)$ & $92 \pm 16$ & $66 \pm 20$ & $<.001$ \\
\hline Mini-Mental State Examination score & $27.1 \pm 3.2$ & $25.6 \pm 3.7$ & .01 \\
\hline Trail-making test score & $65.3 \pm 33.8$ & $71.4 \pm 37.5$ & .32 \\
\hline $\begin{array}{l} \pm \text { values are mean } \pm \mathrm{SD} \text {. } \\
\mathrm{FVC}=\text { forced vital capacity }\end{array}$ & & & \\
\hline
\end{tabular}

\section{Respiratory Muscle Strength Assessment}

We used a respiratory manometer (MicroRPM, Micro Medical, Kent, United Kingdom) to measure maximum inspiratory pressure $\left(\mathrm{P}_{\operatorname{Imax}}\right)$ and maximum expiratory pressure $\left(\mathrm{P}_{\text {Emax }}\right)$. $\mathrm{P}_{\text {Imax }}$ was measured at functional residual capacity or above, and $\mathrm{P}_{\mathrm{Emax}}$ at the maximum expiratory position or above. Two $\mathrm{P}_{\text {Emax }}$ and $\mathrm{P}_{\text {Imax }}$ maneuvers were performed, and the best value was recorded.

\section{Spinal Alignment Measurement}

To measure spinal alignment we used a computerized spinal measurement tool (SpinalMouse, SpinalMouse Solutions/SG Fisher \& Associates, Las Vegas, Nevada). The subject stands with open legs, and the paraspinal line is measured from the 7th cervical vertebra to the 3rd sacral vertebra; the total of angles formed between the upper and lower vertebral bodies of the first through 12th thoracic vertebrae are considered the thoracic kyphosis angle (Fig. 2). The total of angles formed between the upper and lower vertebral bodies of the first through 5th lumbar vertebrae are considered the lumbar lordosis angle. ${ }^{13}$ Three measurements were performed, and the mean value was used.

\section{Muscle Strength Assessment}

To measure the muscle strength of the upper extremities we used a digital grip dynamometer (Grip-D, Takei Kiki Kogyo, Niigata, Japan) to measure hand grip force. To measure the strength of the quadriceps femoris we used a muscle strength gauge ( $\mu$ TAS, Anima, Tokyo, Japan) at-

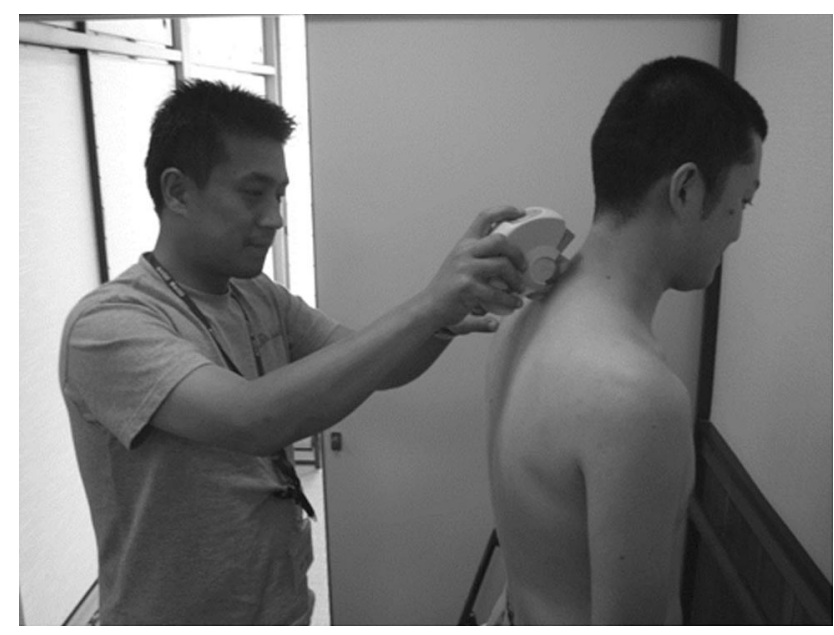

Fig. 2. Assessment of spinal alignment.

tached to a chair, with the subject in the sitting position, with the hip and knee joints bent at $90^{\circ}$. To measure the strength of the trunk, we counted the number of sit-ups the subject could do in 30 seconds. With the knees bent and both elbows crossed in front of the chest, each time the arms touched the right and left thighs and the subject's back touched the floor, it was counted as one sit-up.

We measured toe grasp force with a device (Yagami, Aichi, Japan) developed and studied by Murata et al (Fig. 3). ${ }^{14}$ Prior to each measurement we adjusted the device so that the distal phalanges of the great toe and fifth toe and the middle phalanges of the second to fifth toes could be placed on the toe grasp bar. With this device, the 


\section{Factors That Delay COPD Detection in the General Elderly Population}

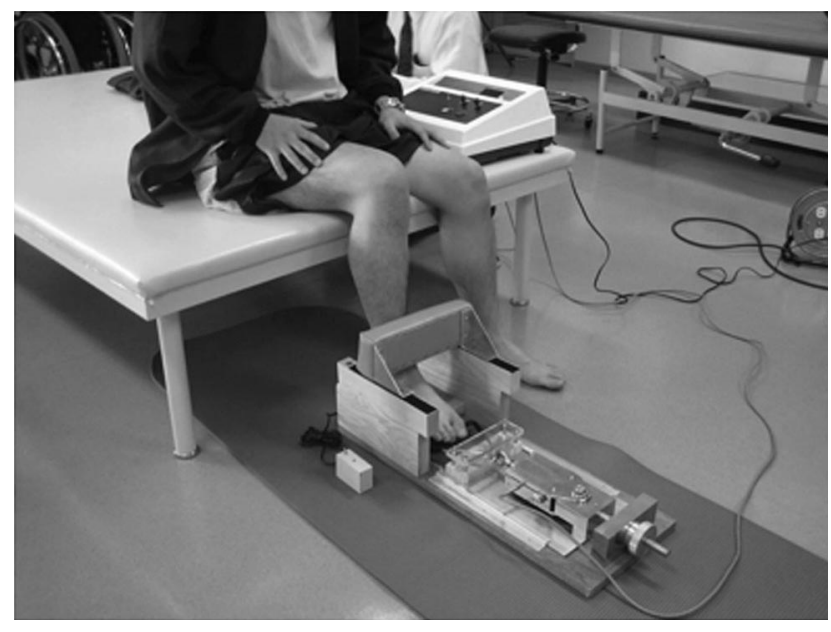

Fig. 3. Assessment of toe grasp force.

toes push the bar downward. Toe grasp force was measured twice, and the best value was recorded.

\section{Skeletal Muscle Mass Measurement}

We used a 4-electrode dual-frequency body composition meter (DC-320, Tanita, Tokyo, Japan) to measure skeletal muscle mass via bioelectrical impedance analysis. The subject stood upright on the device. Skeletal muscle mass was measured once.

\section{Balance Assessment}

We used a stabilometer (GS-31, Anima, Tokyo, Japan) to assess balance. In the standing position, with eyes open, the subject was instructed: While looking at the mark (which was at a point $2 \mathrm{~m}$ away from the subject's eyes, at eye level), stand upright while closing your legs and bringing your arms against the sides of your body. This measurement lasted for 30 seconds, and the total length of the centroid tracing was assessed twice. One-leg standing time was measured twice for the right leg and the left leg, with the same procedure as for assessment of body sway. The best value was recorded.

\section{Walking Ability Assessment}

The subject was instructed to walk at his or her maximum walking speed on a flat floor, $11 \mathrm{~m}$ long. We used a stopwatch to measure the time required for the subject to pass the halfway point ( $5 \mathrm{~m}$ from the start point), and calculated the maximum walking speed. In the $10-\mathrm{m}$ hurdle walk, 6 sponge hurdles ( $20 \mathrm{~cm}$ tall) were placed at $2-\mathrm{m}$ intervals on a $10-\mathrm{m}$ straight line, and we measured the time required to walk the hurdle course. In the timed up-and-go test ${ }^{15,16}$ we measured the time required to arise from the
Table 2. Questionnaire on Activities of Daily Living*

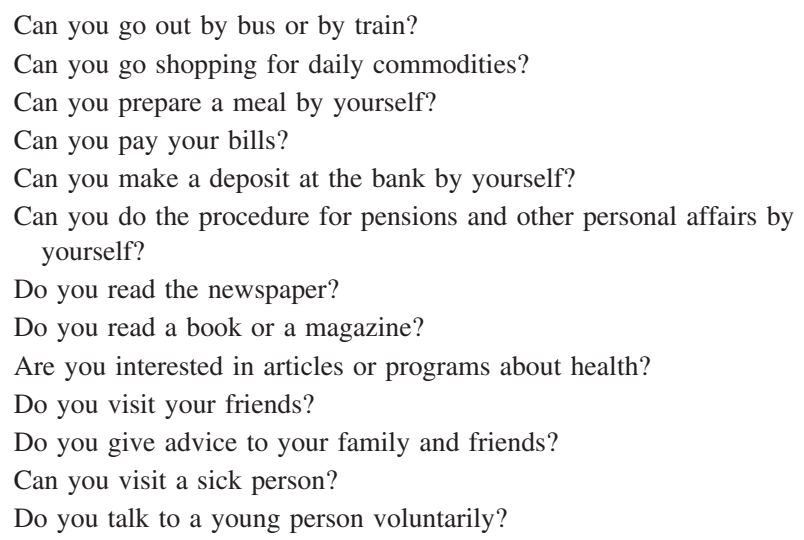

* Based on the Tokyo Metropolitan Institute of Gerontology index. The activities of daily living assessment is based on the number of yes responses. The highest score is 13 points.

seated position, walk to a target placed $3 \mathrm{~m}$ away from the chair, and return to the seated position. In the 6-minute walk test the subject walked as far as possible in $6 \mathrm{~min}$. We conducted the 6-minute walk test once. The other tests were performed twice, and we recorded the best value.

\section{Quality of Life Assessment}

We used a visual analog scale to assess the subject's views on 4 QOL domains: sense of well-being, life satisfaction level, purpose of life, and human relationships. The subject indicated his or her subjective assessment on a 100 -mm straight line, on which zero indicated the most negative response and 100 indicated the most positive response. ${ }^{17-20}$ To assess performance of activities of daily living we used the Tokyo Metropolitan Institute of Gerontology questionnaire on activities of daily living (Table 2). The score was the total number of yes responses.

\section{Statistical Analysis}

With statistics software (SPSS 17.0, SPSS Japan, Tokyo, Japan) we analyzed the data from the healthy-subjects group and the airway-obstruction group with the paired $t$ test. Values are expressed as mean $\pm \mathrm{SD}$. A $P$ value $<.05$ was considered statistically significant.

\section{Results}

\section{Symptoms}

The only symptom we observed was chronic sputum in 2 patients in the airway-obstruction group who had stage II COPD. All other patients in the airway-obstruction group 
Table 3. Strength, Exercise, and Walking Performance*

\begin{tabular}{|c|c|c|c|}
\hline & $\begin{array}{l}\text { Healthy Subjects } \\
\quad(n=60)\end{array}$ & $\begin{array}{l}\text { Airway-Obstruction } \\
\text { Subjects } \\
(n=60)\end{array}$ & $P$ \\
\hline \multicolumn{4}{|l|}{ Muscle Strength (kg) } \\
\hline Hand grip force & $25.8 \pm 7.0$ & $22.9 \pm 7.3$ & .02 \\
\hline Quadriceps femoris & $21.4 \pm 8.3$ & $20.7 \pm 7.6$ & .59 \\
\hline Sit-ups (mean \pm SD no.) & $4.3 \pm 4.3$ & $2.9 \pm 4.2$ & .56 \\
\hline Maximum inspiratory pressure $\left(\mathrm{cm} \mathrm{H}_{2} \mathrm{O}\right)$ & $56 \pm 31$ & $43 \pm 26$ & .02 \\
\hline Maximum expiratory pressure $\left(\mathrm{cm} \mathrm{H}_{2} \mathrm{O}\right)$ & $67 \pm 28$ & $49 \pm 18$ & $<.001$ \\
\hline Muscle mass (kg) & $31.3 \pm 10.4$ & $33.1 \pm 8.0$ & .31 \\
\hline Thoracic kyphosis angle (degrees) & $37 \pm 10$ & $41 \pm 12$ & .11 \\
\hline Lumber lordosis angle (degrees) & $-13 \pm 11$ & $-10 \pm 14$ & .14 \\
\hline One-leg standing time $(\mathrm{s})$ & $31 \pm 33$ & $28 \pm 33$ & .67 \\
\hline Total trace length $(\mathrm{cm})$ & $52 \pm 19$ & $62 \pm 23$ & .35 \\
\hline Toe grasp force $(\mathrm{kg})$ & $6.8 \pm 3.0$ & $6.4 \pm 3.1$ & .54 \\
\hline Maximum walking speed (m/min) & $119 \pm 25$ & $105 \pm 29$ & .005 \\
\hline Walking time on 10-m hurdle (s) & $7 \pm 2$ & $9 \pm 5$ & .04 \\
\hline Up and go test (s) & $5 \pm 1$ & $6 \pm 2$ & .11 \\
\hline 6-min-walk test (m) & $437 \pm 77$ & $415 \pm 123$ & .31 \\
\hline
\end{tabular}

had no symptoms (chronic cough, chronic sputum, or exertional dyspnea)

\section{Prevalence and Severity of COPD}

In 60 of the 408 subjects who could perform the respiratory function test, the $\mathrm{FEV}_{1} / \mathrm{FVC}$ was $<70 \%$. The prevalence of COPD was $15 \%$. The GOLD COPD severity distribution was: stage I (16 patients, 27\%); stage II (33 patients, 55\%); stage III (11 patients, 18\%); and stage IV (no patients). Therefore, patients with mild (stage I) to severe (stage III) COPD were successfully detected.

\section{Comparisons of Healthy-Subjects Group and Airway-Obstruction Group}

Table 1 shows the anthropometry, spirometry, MiniMental State Examination, and trail-making test data. The airway-obstruction group had significantly lower body mass index, $\mathrm{FEV}_{1}, \mathrm{FEV}_{1} / \mathrm{FVC}$, and Mini-Mental State Examination score. There were no significant differences between the groups in FVC, percent-of-predicted FVC, or trail-making test score.

Table 3 shows the strength, exercise, and walking performance results. The airway-obstruction group had significantly lower hand grip force, $\mathrm{P}_{\text {Imax }}, \mathrm{P}_{\text {Emax }}$, instantaneous walking ability (ie, maximum walking speed), and 10 -m hurdle walk time. There was no significant difference in the other measured variables. Table 4 shows the QOL and ADL results. There were no significant differ-
Table 4. Subjective Quality of Life and Activities of Daily Living Scores*

\begin{tabular}{llll}
\hline \hline & $\begin{array}{c}\text { Healthy } \\
\text { Subjects } \\
(n=60)\end{array}$ & $\begin{array}{c}\text { Airway- } \\
\text { Obstruction } \\
\text { Subjects } \\
(n=60)\end{array}$ & $P$ \\
\hline Visual Analog Scale & & & \\
$\quad$ Sense of well-being & $62.5 \pm 18.7$ & $61.0 \pm 21.4$ & .67 \\
Life satisfaction level & $66.6 \pm 20.6$ & $67.3 \pm 24.4$ & .87 \\
Purpose of life & $69.0 \pm 21.9$ & $74.2 \pm 23.2$ & .21 \\
$\quad$ Human relationships & $74.3 \pm 23.9$ & $77.6 \pm 21.4$ & .43 \\
Activities of daily living & $12.0 \pm 1.7$ & $11.0 \pm 2.0$ & .005 \\
& & & \\
* Values are mean \pm SD. & & & \\
\hline
\end{tabular}

ences in QOL, but the ADL values were significantly higher in the healthy-subjects group.

\section{Discussion}

In clinical settings we frequently encounter patients with moderate to severe COPD, but it is difficult to provide them with effective exercise training and to improve their exercise performance. In the present study we did not make a differential diagnosis from other disorders (eg, asthma or respiratory infection) because we had excluded people with diagnosed respiratory diseases. Our study suggests that spirometry in elderly subjects can detect undiagnosed COPD. Currently, primary care physicians insufficiently recognize the importance of spirometry for early 


\section{Factors That Delay COPD Detection in the General Elderly Population}

COPD detection, ${ }^{21,22}$ so programs are needed to enable professionals to precisely perform spirometry. ${ }^{23,24}$ Technically, it is not difficult to perform spirometry in communities where many elderly individuals reside, so screening spirometry has a potentially great contribution to early COPD detection.

Walking endurance was well preserved in our subjects, as indicated by no significant difference between the groups in the 6-minute walk test. Furthermore, none of the subjects complained of a decrease in QOL or ability to do their ADLs, which caused them to be unaware of their COPD. Pinto-Plata et al ${ }^{11}$ found no significant difference in exercise performance between stage I COPD patients and healthy subjects. Therefore, we think it is difficult for COPD patients to notice the disease through decreased exercise performance. The proportion of muscle fibers, especially type I fibers, has been reported to decrease in COPD patients, compared to healthy elderly subjects, ${ }^{25-27}$ and the decrease is associated with the severity of COPD. ${ }^{25,27}$ We speculate that the relevant decrease is not as intense in early-stage COPD patients, which makes it more difficult for them to notice a decrease in walking endurance from muscle fatigue or other clinical manifestations, compared to healthy subjects.

Furthermore, $4-35 \%$ of COPD patients have muscular atrophy. ${ }^{28-30}$ Atrophy of the quadriceps femoris reduces exercise performance ${ }^{31,32}$ and QOL. ${ }^{33}$ However, we found no significant difference in quadriceps femoris strength or muscle mass, so we think there was no marked muscular atrophy in our airway-obstruction group, which probably also made them less sensitive to decreases in walking endurance and QOL.

Walking endurance and QOL in our COPD patients were well preserved, although there was a significant difference in instantaneous walking ability between the healthy and airway-obstruction subjects. Furthermore, muscle strength was significantly less in the distal than the proximal muscles in the extremities. We suspect that these are the primary factors that delay COPD diagnosis, because the patients are unaware or less aware of the disease, which hampers their motivation for seeking medical care and delays COPD detection.

Our data also indicate that instantaneous walking ability, muscle strength in the distal extremities, and respiratory muscle strength had started to decline in the airwayobstruction subjects, despite that few of them had symptoms (eg, chronic cough, chronic sputum, or exertional dyspnea). Decreased distal muscle strength in the extremities involves many points to be elucidated. COPD patients with decreased exercise performance have been reported to have well preserved hand grip force, similar to healthy subjects. ${ }^{34}$ However, most previous studies on muscular functions in COPD patients examined the quadriceps femoris and the diaphragm, and few studies have examined distal muscle strength in the extremities. Our data suggest that a decrease in muscle strength occurs first in the distal muscles of the extremities. We presume that initially decreased strength in small distal muscles of the extremities is less likely to impair the person's ability to do ADLs, so the impairment is not highly noticeable.

Regarding respiratory muscle strength, on the other hand, there were significant differences in $\mathrm{P}_{\text {Imax }}$ and $\mathrm{P}_{\text {Emax }}$ between the airway-obstruction and healthy-subjects groups. Changes in muscle fibers have been reported to occur earlier in the diaphragm than in the quadriceps femoris. ${ }^{35}$ Furthermore, patients with mild to moderate COPD have atrophy of the respiratory muscles. ${ }^{36}$ These facts explain the significant difference we found in respiratory muscle strength between the airway-obstruction and healthy-subjects groups.

Ofir et $\mathrm{al}^{37}$ reported that the effects of the abnormal dynamic ventilatory system are already manifested in patients with stage I COPD. Dynamic hyperinflation causes exertional dyspnea, ${ }^{38}$ but in early-stage COPD the hyperinflation-induced effects on the diaphragm and intercostal respiratory muscles readily occur, rather than subjective symptoms, which possibly leads to decreases in respiratory muscle strength. Previous studies have reported that, in patients with severe COPD, respiratory muscle strength is significantly related to exercise performance and exertional dyspnea, ${ }^{39-41}$ ADL performance, ${ }^{42}$ and QOL. ${ }^{39,43} \mathrm{We}$ conjecture that the abnormalities in the dynamic ventilatory system in our airway-obstruction group were manifested not as subjective symptoms but as decreases in respiratory muscle strength, which made ADL performance impairment more difficult to detect.

Many studies have demonstrated the clinical efficacy of exercise training programs for patients with respiratory disease. ${ }^{4-6}$ We think pulmonary rehabilitation programs for COPD patients should include resistance training for the distal muscles of the extremities, ${ }^{44}$ the respiratory muscles, and instantaneous walking ability.

In consideration of the fact that respiratory muscle strength started to decrease in COPD patients, as manifested by decreased $\mathrm{P}_{\mathrm{Imax}}$ and $\mathrm{P}_{\text {Emax }}$, we speculate that prompt implementation of respiratory muscle training might delay decreases in ADL performance and QOL. There is moderate evidence of the benefits of such exercise programs on exercise performance, ${ }^{39-41}$ ADL performance, ${ }^{42}$ and QOL. ${ }^{39,43}$ Furthermore, respiratory muscle training programs and instantaneous walking ability are clinically relevant when determining the composition of respiratory rehabilitation programs in medical care.

\section{Limitations}

First, we did not perform a bronchodilator test to make a differential diagnosis of COPD. However, we did take 


\section{Factors That Delay COPD Detection in the General Elderly Population}

careful personal and family medical histories and excluded subjects with known asthma. But it is possible that we included some patients with asthma in the airway-obstruction group. Second, the study population was elderly subjects who participated in a health promotion program, so they had high consciousness about their health. Middleage patients with COPD were excluded, so our study applies only to elderly subjects, not all ages of COPD patients in the general population. Third, we did not conduct a maximal exercise stress test, but, instead, the 6-minute walk test, which is a submaximal exercise stress test.

In the future we will conduct a prospective longitudinal study by following up the subjects in the present study's airway-obstruction group, and those patients will gain a definite diagnosis and undergo treatment (eg, pulmonary rehabilitation). We will also follow the natural course of COPD in a group without diagnosis and treatments. We will examine the time-course changes in their respiratory function, physical performance, and QOL.

\section{Conclusions}

Walking endurance, QOL, and proximal muscle strength in the extremities were well preserved in our COPD patients, although there was a significant difference in instantaneous walking ability between the healthy-subjects group and the airway-obstruction group. We suspect that the good preservation of these variables is the primary factor that delays COPD detection, because these individuals are unaware of the disease and therefore not motivated to seek medical care. In primary healthcare for the general elderly population, screening spirometry is needed to detect COPD, and we believe that health screening programs with spirometry should be implemented to detect and stage early COPD.

\section{ACKNOWLEDGMENTS}

We thank Michie Ohyama, Welfare Equipment Net, for coordinating the study, and Satoshi Sakima MD for critical review of the manuscript.

\section{REFERENCES}

1. Rabe KF, Hurd S, Anzueto A, Barnes PJ, Buist SA, Calverley P, et al. Global strategy for the diagnosis, management, and prevention of chronic obstructive pulmonary disease: GOLD executive summary. Am J Respir Crit Care Med 2007;176(6):532-555.

2. Chee A, Sin DD. Treatment of mild chronic obstructive pulmonary disease. Int J Chron Obstruct Pulmon Dis 2008;3(4):563-573.

3. Benfield T, Lange P, Vestbo J. COPD stage and risk of hospitalization for infectious disease. Chest 2008;134(1):46-53.

4. Puhan MA, Schünemann HJ, Frey M, Scharplatz M, Bachmann LM. How should COPD patients exercise during respiratory rehabilitation? Comparison of exercise modalities and intensities to treat skeletal muscle dysfunction. Thorax 2005;60(5):367-375.

5. Gimenez M, Servera E, Vergara P, Bach JR, Polu JM. Endurance training in patients with chronic obstructive pulmonary disease: a comparison of high versus moderate intensity. Arch Phys Med Rehabil 2000;81(1):102-109.

6. Karapolat H, Atasever A, Atamaz F, Kirazli Y, Elmas F, Erdinc E. Do the benefits gained using a short-term pulmonary rehabilitation program remain in COPD patients after participation? Lung 2007; 185(4):221-225.

7. Rossi G, Florini F, Romagnoli M, Bellantone T, Lucic S, Lugli D, et al. Length and clinical effectiveness of pulmonary rehabilitation in outpatients with chronic airway obstruction. Chest 2005;127(1):105109.

8. Fukuchi Y, Nishimura M, Ichinose M, Adachi M, Nagai A, Kuriyama T, et al. COPD in Japan: Nippon COPD Epidemiology study. Respirology 2004;9(4):458-465.

9. Bednarek M, Maciejewski J, Wozniak M, Kuca P, Zielinski J. Prevalence, severity and underdiagnosis of COPD in the primary care setting. Thorax 2008;63(5):402-407.

10. Buist AS, McBurnie MA, Vollmer WM, Gillespie S, Burney P, Mannino DM, et al. International variation in the prevalence of COPD (the BOLD Study): a population-based prevalence study. Lancet 2007;370(9589):741-750.

11. Pinto-Plata VM, Celli-Cruz RA, Vassaux C, Torre-Bouscoulet L, Mendes A, Rassulo J, et al. Differences in cardiopulmonary exercise test results by American Thoracic Society/European Respiratory Society-Global Initiative for Chronic Obstructive Lung Disease stage categories and gender. Chest 2007;132(4):1204-1211.

12. Folstein, MF, Folstein SE, McHugh PR. "Mini-mental state". A practical method for grading the cognitive state of patients for the clinician. J Psychiatr Res 1975;12(3):189-198.

13. Mannion AF, Knecht K, Balaban G, Dvorak J, Grob D. A new skin-surface device for measuring the curvature and global and segmental ranges of motion of the spine; reliability of measurements and comparison with data reviewed from the literature. Eur Spine $\mathrm{J}$ 2004;13(2):122-136.

14. Murata S, Kai Y, Tanaka S, Yamazaki S. Development of a strain gauge based foot-gripping force meter. Rigakuryouhoukagaku 2006; 21(4):363-367. Article in Japanese.

15. Podsiadlo D, Richardson S. The timed "up \& go": a test of basic functional mobility for frail elderly persons. J Am Geriatr Soc 1991; 39(2):142-148.

16. Newton RA. Balance screening of an inner city older adult population. Arch Phys Med Rehabil 1997;78(6):587-591.

17. McCormack HM, Horne DJ, Sheather S. Clinical applications of visual analogue scales; a critical review. Phychol Med 1988;18(4): 1007-1019.

18. Fayers PM, Jones DR. Measuring and analyzing quality of life in cancer clinical trials; a review. Stat Med 1983;2(4):429-446.

19. Hisashige A, Mikasa H, Katayama T. Description and evaluation of health-related quality of life among the general public in Japan by the EuroQol. J Med Invest 1998;46(1-4):123-129.

20. Kimura T, Hayashida K, Araki Y, Morita T, Yamaguchi N, Eboshida A. How valid is the self-administered visual analogue scale for assessing the health status of elderly people? Hiroshima J Med Sci 2008;57(3-4):85-92.

21. Bolton CE, Ionescu AA, Edwards PH, Faulkner TA, Edwards SM, Shale DJ. Attaining a correct diagnosis of COPD in general practice. Respir Med 2005;99(4):493-500.

22. Caramori G, Bettoncelli G, Tosatto R, Arpinelli F, Visonà G, Invernizzi $\mathrm{G}$, et al. Underuse of spirometry by general practitioners for the diagnosis of COPD in Italy. Monaldi Arch Chest Dis 2005;63(1): 6-12.

23. Schermer TR, Jacobs JE, Chavannes NH, Hartman J, Folgering HT, Bottema BJ, et al. Validity of spirometric testing in a general practice population of patients with chronic obstructive pulmonary disease. Thorax 2003;58(10):861-866. 


\section{Factors That Delay COPD Detection in the General Elderly Population}

24. Eaton T, Withy S, Garrett JE, Mercer J, Whitlock RM, Rea HH. Spirometry in primary care practice: the importance of quality assurance and the impact of spirometry workshop. Chest 1999;116(2): 416-423.

25. Gosker HR, Zeegers MP, Wouters EF, Schols AM. Muscle fiber type shifting in the vastus lateralis of patients with COPD is associated with disease severity: a systematic review and meta-analysis. Thorax 2007;62(11):944-949.

26. Jobin J, Maltais F, Doyon JF, LeBlanc P, Simard PM, Simard AA, et al. Chronic obstructive pulmonary disease: capillarity and fibertype characteristics of skeletal muscle. J Cardiopulm Rehabil 1998; 18(6):432-437.

27. Whittom F, Jobin J, Simard PM, Leblanc P, Simard C, Bernard S, et al. Histochemical and morphological characteristics of the vastus lateralis muscle in patients with chronic obstructive pulmonary disease. Med Sci Sports Exerc 1998;30(10):1467-1474.

28. Coronell C, Orozco-Levi M, Gea J. COPD and body weight in a Mediterranean population. Clin Nutr 2002;21(5):437.

29. Schols AM, Soeters PB, Dingemans AM, Mostert R, Frantzen PJ, Wouters EF. Prevalence and characteristics of nutritional depletion in patients with stable COPD eligible for pulmonary rehabilitation. Am Rev Respir Dis 1993;147(5):1151-1156.

30. Vestbo J, Prescott E, Almdal T, Dahl M, Nordestgaard BG, Andersen $\mathrm{T}$, et al. Body mass, fat-free body mass, and prognosis in patients with chronic obstructive pulmonary disease from a random population sample: findings from the Copenhagen City Heart Study. Am J Respir Crit Care Med 2006;173(1):79-83.

31. Bernard S, LeBlanc P, Whittom F, Carrier G, Jobin J, Belleau R, et al. Peripheral muscle weakness in patients with chronic obstructive pulmonary disease. Am J Respir Crit Care Med 1998;158(2):629_ 634 .

32. Vilaro J, Rabinovich R, Gonzalez-deSuso JM, Troosters T, Rodríguez D, Barberà JA, et al. Clinical assessment of peripheral muscle function in patients with chronic obstructive pulmonary disease. Am J Phys Med Rehabil 2009;88(1):39-46.

33. Mostert R, Goris A, Weling-Scheepers C, Wouters EF, Schols AM. Tissue depletion and health related quality of life in patients with chronic obstructive pulmonary disease. Respir Med 2000;94(9):859_ 867.
34. Gea JG, Pasto M, Carmona MA, Orozco-Levi M, Palomeque J, Broquetas J. Metabolic characteristics of the deltoid muscle in patients with chronic obstructive pulmonary disease. Eur Respir J 2001; 17(5):939-945.

35. Doucet M, Debigare R, Joanisse DR, Cote C, Leblanc P, Gregoire J, et al. Adaptation of the diaphragm and the vastus lateralis in mildto-moderate COPD. Eur Respir J 2004;24(6):971-979.

36. Ottenheijm CA, Heunks LM, Sieck GC, Zhan WZ, Jansen SM, Degens $\mathrm{H}$, et al. Diaphragm dysfunction in chronic obstructive pulmonary disease. Am J Respir Crit Care Med 2005;172(2):200-205.

37. Ofir D, Laveneziana P, Webb KA, Lam YM, O'Donnell DE. Mechanisms of dyspnea during cycle exercise in symptomatic patients with GOLD stage I chronic obstructive pulmonary disease. Am J Respir Crit Care Med 2008;177(6):622-629.

38. O'Donnell DE, Voduc N. Mechanisms of dyspnea in COPD. In: Mahler DA, O'Donnel DE, editors. Dyspnea: mechanisms, measurement, and management, 2nd edition. Florida: Taylor \& Francis; 2005:29-58.

39. Sánchez Riera H, Montemayor Rubio T, Ortega Ruiz F, Cejudo Ramos P, Del Castillo Otero D, Elias Hernandez T, et al. Inspiratory muscle training in patients with COPD: effect on dyspnea, exercise performance, and quality of life. Chest 2001;120(3):748-756.

40. Lisboa C, Villafranca C, Leiva A, Cruz E, Pertuzé J, Borzone G. Inspiratory muscle training in Chronic airflow limitation: effect on exercise performance. Eur Respir J 1997;10(3):537-542.

41. Weiner P, Magadle R, Beckerman M, Weiner M, Berar-Yanay N. Comparison of specific expiratory, inspiratory and combined muscle training programs in COPD. Chest 2003;124(4):1357-1364.

42. Lötters F, van Tol B, Kwakkel G, Gosselink R. Effects of controlled inspiratory muscle training in patients with COPD: a meta analysis. Eur Respir J 2002;20(3):570-576.

43. Beckerman M, Magadle R, Weiner M, Weiner P. The effects of 1 year of specific inspiratory muscle training in patients with COPD. Chest 2005;128(5):3177-3182.

44. Troosters T, Probst VS, Crul T, Pitta F, Gayan-Ramirez G, Decramer $\mathrm{M}$, et al. Resistance training prevents deterioration in quadriceps muscle function during acute exacerbations of chronic obstructive pulmonary disease. Am J Respir Crit Care Med 2010;181(10):1072_ 1077. 